\title{
Mit Freiheit und Werten zu Wohlstand
}

\author{
Zwölf Thesen eines Pendlers zwischen Wirtschaft und Politik
}

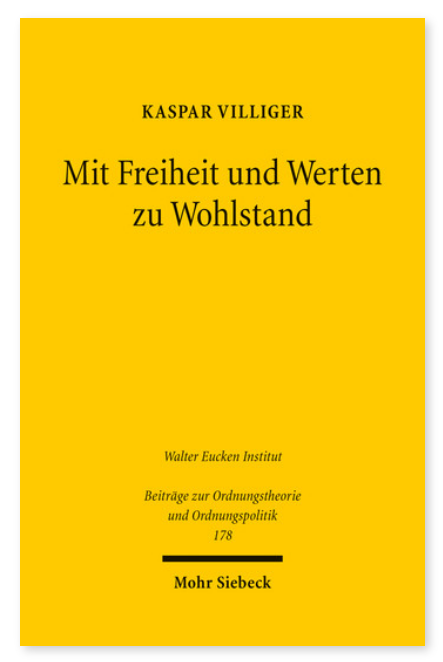

2015. 91 Seiten. BOrd 178

ISBN 978-3-16-153617-5

DOI 10.1628/978-3-16-153617-5

eBook PDF 29,00€

ISBN 978-3-16-153616-8

Broschur 29,00€
Warum braucht nicht nur der Staat die Marktwirtschaft, sondern die Marktwirtschaft auch den Staat? Warum bewirken Gesetze häufig anderes, als der Gesetzgeber erwartet? Wie entsteht Wohlstand? Kaspar Villiger verdichtet seine Erfahrungen aus 46 Jahren Berufsleben als Unternehmer, Verwaltungsrat global tätiger Konzerne, Verteidigungs- und Finanzminister sowie Schweizer Bundespräsident in zwölf Thesen und sucht Antworten auf diese und andere Fragen. Er fragt, warum sich die Wirtschaft auch von ethischen Kriterien leiten lassen soll und wie der Föderalismus strukturiert sein muss, damit auch die Gliedstaaten Selbstverantwortung wahrnehmen. Und er analysiert, warum Demokratien Selbstbindungen brauchen, um nicht im Schuldensumpf zu versinken. Dabei untermauert Villiger seine erfahrungsbasierten Einsichten mit Erkenntnissen der modernen Ökonomik. Seine Überlegungen sind ein leidenschaftliches Plädoyer für eine freiheitliche Gesellschaftsordnung.

Kaspar Villiger Geboren 1941; 1966 Diplomingenieur ETH; 1989-2003 Bundesrat (zuerst Verteidigungsminister, dann Finanzminister); 1995 \& 2002 Bundespräsident; 2004-09 Verwaltungsrat Nestlé, Swiss Re und Neue Zürcher Zeitung; 2009-12 Verwaltungsratspräsident UBS; 2004 Ehrendoktorwürde der Universität Luzern; seit 2009 Chairman der UBS Foundation of Economics in Society.
Jetzt bestellen:

https://mohrsiebeck.com/buch/mit-freiheit-und-werten-zu-wohlstand-9783161536175?no_cache=1 order@mohrsiebeck.com

Telefon: $+49(0) 7071-923-17$

Telefax: $+49(0) 7071-51104$ 